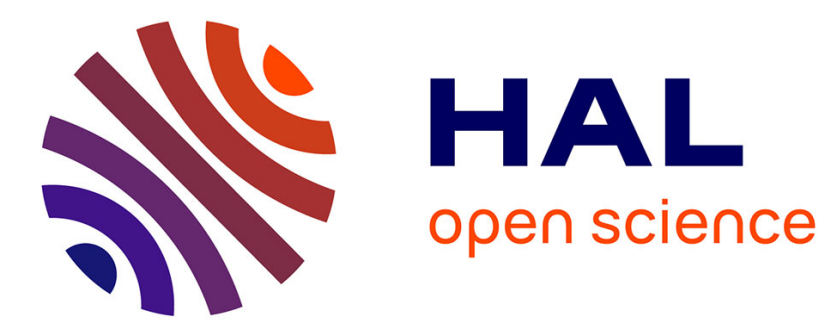

\title{
The Effect of Strain Rate on the Compressive Stress-Strain Properties of PEEK and Epoxy Carbon Fibre Composites
}

\author{
D. Parry
}

\section{To cite this version:}

D. Parry. The Effect of Strain Rate on the Compressive Stress-Strain Properties of PEEK and Epoxy Carbon Fibre Composites. Journal de Physique IV Proceedings, 1997, 07 (C3), pp.C3-605-C3-610. 10.1051/jp4:19973104 . jpa-00255388

\section{HAL Id: jpa-00255388 https://hal.science/jpa-00255388}

Submitted on 1 Jan 1997

HAL is a multi-disciplinary open access archive for the deposit and dissemination of scientific research documents, whether they are published or not. The documents may come from teaching and research institutions in France or abroad, or from public or private research centers.
L'archive ouverte pluridisciplinaire HAL, est destinée au dépôt et à la diffusion de documents scientifiques de niveau recherche, publiés ou non, émanant des établissements d'enseignement et de recherche français ou étrangers, des laboratoires publics ou privés. 


\title{
The Effect of Strain Rate on the Compressive Stress-Strain Properties of PEEK and Epoxy Carbon Fibre Composites
}

\author{
D.J. Parry
}

Department of Physics, Loughborough University, Loughborough, Leicestershire LE11 3TU, U.K.

\begin{abstract}
The dynamic compressive behaviour of two AS4 carbon fibre composite systems has been studied at room temperature at strain rates from about $10^{-3} \mathrm{~s}^{-1}$ to $10^{3} \mathrm{~s}^{-1}$. One system (APC2) had a thermoplastic PEEK matrix, while the other system (EC) had a thermoset epoxy resin matrix. Transverse unidirectional and transverse cross-ply fibre configurations were used for each system. Both configurations showed greater stiffness, linearity and strength at high rates than at low rates, but the high rate behaviour of the APC2 was more complex than that of the EC. The measured Young's modulus values were in good agreement with theoretical predictions.

Résumé. Le comportement sous pression dynamique de deux systèmes de AS4 fibre de carbon transversal a été étudié à température ambiante, entre des vitesses de déformation de $10^{-3} \mathrm{~s}^{-1} \mathrm{j}^{\prime} \mathrm{usqu}$ à $10^{3} \mathrm{~s}^{-1}$. Un composite APC2 avait une matrice PEEK, tandis que l'autre EC avait une matrice de résine époxyde. A des vitesses de déformation élevées les deux composites ont montrés plus de rigidité, linéairité et resistance, mais le comportement du APC2 a vitesse de déformation elevée était plus compliqué que celui du EC. Les valuers mesurées du module de Young étaient en bon accord avec les prédictions théoriques.
\end{abstract}

\section{INTRODUCTION}

Carbon fibre composites have found wide application as structural materials, especially in the aerospace industry [1]. The high strain rate behaviour of such materials is of great importance when there is impact loading. The present paper describes a comparative study of the transverse compressive behaviour of two continuous carbon-fibre systems at high and low strain-rates. One system (APC2) consists of Hercules Magnamite AS4 carbon fibres in a thermoplastic polyetheretherkeytone (PEEK) matrix, while the other system (EC) uses AS4 fibres in a thermoset epoxy resin matrix (type 934, code 89). The fibre volume fraction was $62 \%$ for each system. High strain rates were obtained using the split Hopkinson pressure bar (SHPB) technique in which strain rates covering the range of about $10^{2}$ to $10^{4} \mathrm{~s}^{-1}$ are achievable $[2,3]$.

\section{EXPERIMENTAL METHODS}

\subsection{The Test Specimens}

The test specimens were in the form of small solid cylinders with nominal dimensions of $8 \mathrm{~mm}$ diameter by $4 \mathrm{~mm}$ thickness cut from 32-ply composite plates. The specimen faces were flat to within $1 \mu \mathrm{m}$ and parallel to about $10 \mu \mathrm{m}$. Two types of transverse fibre configuration were used for each system: (a) transverse unidirectional (TU), in which all the fibres were aligned in the same direction, and (b) transverse cross-ply (TC) in which the fibres were at right angles in alternate plies. For each configuration the direction of the compressive loading was perpendicular to the specimen faces (i.e. to the fibre planes). 


\subsection{Compression Tests}

All experiments were carried out at room temperature using two different types of test equipment: a conventional $50 \mathrm{kN}$ screw-driven Instron machine for low strain rates of about $10^{-3} \mathrm{~s}^{-1}$, and a split Hopkinson pressure bar system for high strain rates of about $10^{3} \mathrm{~s}^{-1}$.

\subsubsection{The Split Hopkinson Pressure Bar System (SHPB)}

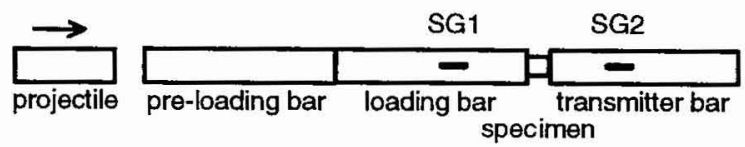

Figure 1: The three-bar SHPB system.

Figure 1 is a schematic diagram of the novel three-bar Loughborough system [4]. The specimen is sandwiched between two $1 \mathrm{~m}$ length, high-strength maraging steel bars (the loading and transmitter pressure bars). A pre-loading bar of the same diameter as the pressure bars $(12.7 \mathrm{~mm})$, but made of a lower strength steel, is positioned before the loading bar. A $25 \mathrm{~cm}$ length steel projectile is fired at the preloading bar at speeds up to $35 \mathrm{~m} \mathrm{~s}^{-1}$ from a gas gun. The pre-loading bar dampens the high frequency oscillations on the stress pulse created by the impact; a smooth pulse of amplitude up to $700 \mathrm{MPa}$ and a duration of about $100 \mu$ s then passes into the actual loading bar. Part of this pulse is reflected from the specimen while the rest passes through into the transmitter bar.

The incident (loading), reflected and transmitted pulses are recorded by etched-foil resistance strain gauges SG1 and SG2, mounted axially on the surface of the pressure bars at $40 \mathrm{~cm}$ from the specimen. SG1 records the incident and reflected pulses without overlap, and the transmitted pulse reaches SG2 at the same time as the reflected pulse arrives at SG1. The strain gauges are connected via bridge circuits to a two-channel digital storage oscilloscope. A microcomputer system is used for analysis of the signals.

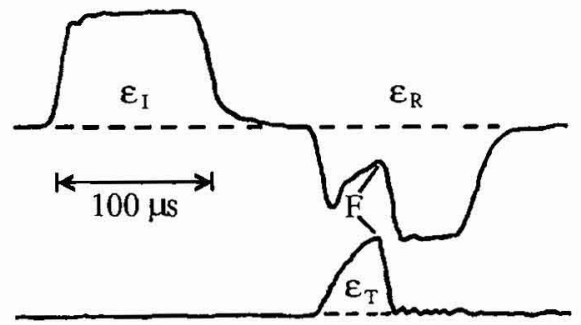

Figure 2: DSO traces for a unidirectional (TU) epoxy composite with a projectile impact speed of $11 \mathrm{~m} \mathrm{~s}^{-1}$.

Figure 2 shows an oscilloscope display of the strain in the pressure bars as a function of time for a unidirectional (TU) epoxy composite with a projectile impact speed of $11 \mathrm{~m} \mathrm{~s}^{-1}$. The upper trace indicates the strain pulses in the loading bar (as recorded by SG1). The compressive (positive) incident strain pulse $\varepsilon_{\mathrm{I}}$ is followed by the tensile (negative) reflected pulse $\varepsilon_{\mathrm{R}}$. The lower trace shows the compressive (positive) transmitted strain pulse $\varepsilon_{\mathrm{T}}$ in the transmitter bar (as recorded by SG2). The occurrence of fracture $(F)$ in the specimen is indicated by the simultaneous abrupt changes in the $\varepsilon_{\mathrm{R}}$ and $\varepsilon_{\mathrm{T}}$ pulses about $40 \mu$ s after they start.

The usual application of one-dimensional wave propagation theory to the SHPB system shows that the engineering values of the specimen stress $\sigma_{S}$ and strain rate $\dot{\varepsilon}_{s}$ are proportional to the transmitted and reflected strain pulses respectively. Integration of the reflected pulse then gives the engineering strain $\varepsilon_{s}$. Since $\dot{\varepsilon}_{s}$ varies during the loading, the results in the present paper have been characterised by the average strain rate given by dividing $\varepsilon_{s}$ at maximum stress by the time taken to reach that stress. 
The engineering values above need to be converted to give the true, or natural, mechanical properties of the materials. By assuming the compressive strains and stresses are positive, then the true specimen strain $\varepsilon$ is related to the engineering strain $\varepsilon_{\mathrm{S}}$ by $\varepsilon=-\ln \left(1-\varepsilon_{\mathrm{S}}\right)$, while the true specimen stress $\sigma$ is related to the engineering stress $\sigma_{\mathrm{s}}$ by $\sigma=\sigma_{s} \exp \left(-2 v \varepsilon_{\mathrm{s}}\right)$, where $v$ is the Poisson's ratio for the specimen. The appropriate values of $v$ are 0.35 and 0.02 for the TU and TC specimens, respectively [5]. All the stress and strain values presented in this paper are the true values.

\section{RESULTS}

\subsection{SHPB Recordings}

The SHPB oscilloscope traces indicate several distinct types of specimen response. As described above, the recording in Figure 2 for a unidirectional (TU) epoxy specimen showed that fracture occurred about $40 \mu \mathrm{s}$ after the start of loading. The analysis of this record indicates a fracture stress of $330 \mathrm{MPa}$ at a strain of $4 \%$ and a strain rate of $940 \mathrm{~s}^{-1}$.

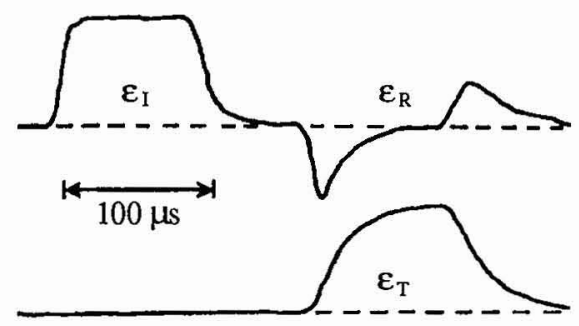

(a)

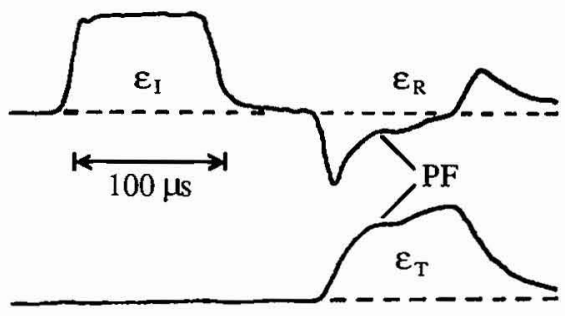

(b)

Figure 3: DSO traces for (a) cross-ply (TC) epoxy at projectile seed of $20 \mathrm{~m} \mathrm{~s}^{-1}$, (b) cross-ply APC2 at speed of $19 \mathrm{~m} \mathrm{~s}^{-1}$.

Other types of recording are shown in Figure 3, in which the strain amplifier gain is half that for Figure 2. Figure 3(a) shows traces for a cross-ply (TC) epoxy specimen with a projectile speed of $20 \mathrm{~m} \mathrm{~s}^{-1}$. No fracture has occurred in this test. There is a continuous smooth increase in $\varepsilon_{\mathrm{T}}$ and a corresponding smooth decrease in $\varepsilon_{R}$ until the loading pulse $\varepsilon_{1}$ starts to decrease. Then $\varepsilon_{T}$ decreases smoothly, indicating a reduction in specimen stress, and $\varepsilon_{\mathrm{R}}$ increases to values above the baseline, indicating elastic strain recovery. The maximum stress and strain are $1030 \mathrm{MPa}$ and $8.5 \%$ respectively, at a strain rate of $1450 \mathrm{~s}^{-1}$. Figure 3(b) is for an APC2 cross-ply (TC) specimen with an impact speed of $19 \mathrm{~m} \mathrm{~s}^{-1}$. The maximum specimen stress and strain are $880 \mathrm{MPa}$ and $10.7 \%$ respectively, at a strain rate of $1610 \mathrm{~s}^{-1}$. There is a partial fracture (PF) after about $40 \mu \mathrm{s}$, as indicated by the discontinuous change in $\varepsilon_{\mathrm{T}}$ and $\varepsilon_{\mathrm{R}}$. However, the specimen does not completely fracture but eventually recovers. This partial fracture is a characteristic of the APC2 and does not occur with the epoxy, where fracture is always sudden and complete.

\subsection{Stress-Strain Behaviour}

\subsubsection{Transverse Unidirectional Specimens $(T U)$}

3.2.1.1 Low Strain Rates Figure 4(a) shows the stress-strain behaviour up to fracture for the epoxy (EC) and APC2 composites at strain rates of $10^{-3} \mathrm{~s}^{-1}$ using the Instron. Two sets of curves are plotted to indicate the extreme range of values obtained from at least four separate experiments for each material. The maximum experimental errors are $\pm 4 \mathrm{MPa}$ in the stress and $\pm 0.1 \%$ in the strain. There is clearly a high degree of consistency in these stress-strain properties. Both composites show linear behaviour up to a strain of about $1 \%$. The epoxy fractures at a higher flow stress than the APC2, but at a lower strain. 


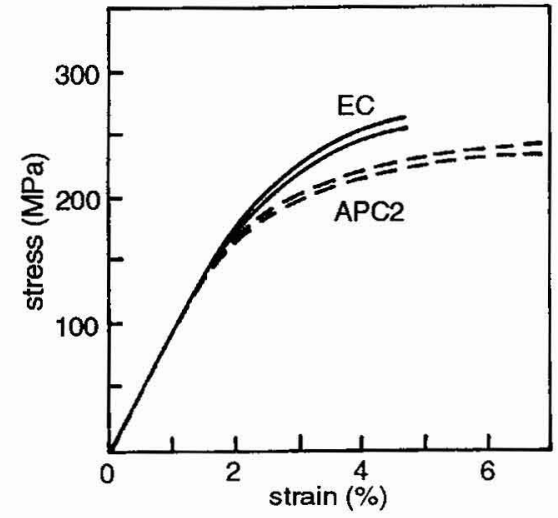

(a)

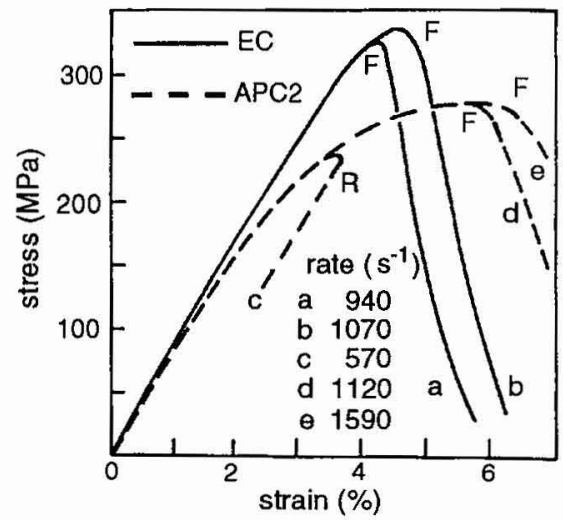

(b)

Figure 4: Stress-strain plots for TU composites: (a) $10^{-3} \mathrm{~s}^{-1}$, and (b) high strain rates.

3.2.1.2 High Strain Rates Unlike the Instron tests, the strain rates for the SHPB method cannot be preselected since the rate is determined by the projectile impact speed and the relative mechanical impedance of the pressure bars and specimen. Also, because of wave propagation within the specimen, the conventional SHPB analysis can lead to an overestimate of the strain for strains less than about $0.5 \%$, i.e. in the region of the stress-strain curve where the Young's modulus would be measured. In the following SHPB analyses, a pulse displacement technique has been used to minimise this effect [6].

Figure 4(b) shows examples of stress-strain plots for the epoxy and APC2 composites, as a function of strain rate. The epoxy curves overlap and are reasonably linear up to fracture $(F)$, the fracture stress being higher for the higher strain rate experiment. Curve (a) is the analysis of the experiment corresponding to Figure 2. The APC2 curve (c) shows that no fracture has occurred, and the specimen has recovered elastically (R). At the higher rates corresponding to curves (d) and (e), the specimens have fractured and, just as for the epoxy, the higher the strain rate the greater is the fracture stress.

\subsubsection{Transverse Cross-Ply Specimens (TC)}

3.2.2.1 Low Strain Rates Figure 5(a) shows stress-strain results up to fracture for the epoxy (EC) and APC2, at strain rates of $10^{-3} \mathrm{~s}^{-1}$. Two sets of curves are plotted for each material to indicate the extreme range of values. The maximum experimental errors are $\pm 10 \mathrm{MPa}$ in the stress and $\pm 0.2 \%$ in the strain. The stress-strain behaviour is almost linear up to fracture for both materials. On average, the epoxy is stiffer than the APC2 but fractures at lower values of stress and strain.

3.2.2.2 High Strain Rates Figure 5(b) shows stress-strain plots for the epoxy and APC2, as a function of strain rate. The epoxy curve (b) is the analysis corresponding to Figure 3(a), while the APC2 curve (f) corresponds to Figure 3(b). The epoxy shows very consistent behaviour: all the results overlap within experimental error up to their respective values of maximum stress indicating that there is no measurable variation in the stiffness over this range of strain rate. There is elastic recovery in cases (a) and (b), whereas there is complete brittle fracture in cases (c) and (d). The APC2 results indicate a more complex behaviour. Curve (e) indicates elastic behaviour followed by elastic recovery. The higher strain rate curve (f) shows that there is a partial fracture followed an increase in stress and then elastic recovery, i.e. the specimen did not disintegrate. A further increase in the strain rate causes an initial partial fracture followed by a large increase in stress up the point of complete fracture (curve g). At the highest strain rate used, the partial fracture is delayed but then is very shortly followed by complete fracture (curve $h$ ). 


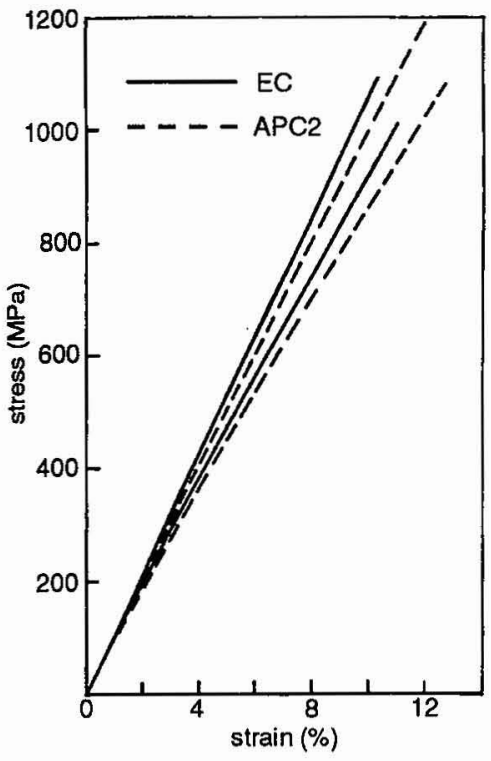

(a)

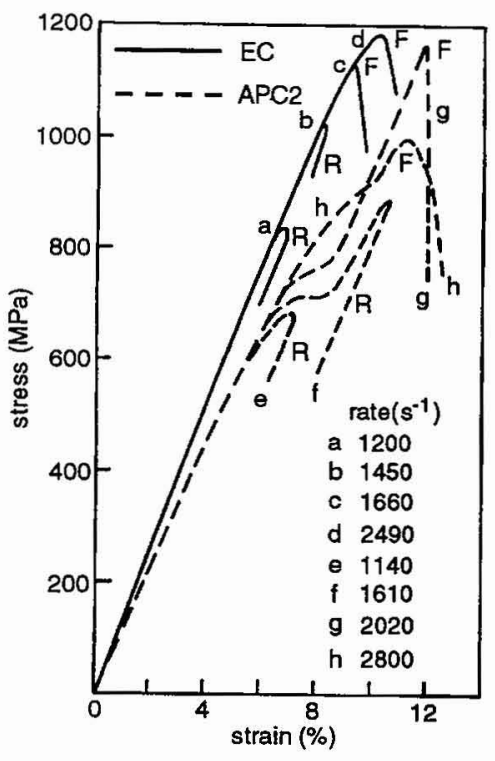

(b)

Figure 5: Stress-strain plots for TC composites: (a) $10^{-3} \mathrm{~s}^{-1}$, and (b) high strain rates.

\section{DISCUSSION}

\subsection{Stress-Strain Behaviour}

Figure 4 shows that for the unidirectional (TU) composites the strain to fracture for the epoxy composite is virtually the same under low and high strain rate conditions, whereas the fracture strain is reduced at high rates for the PEEK composite. At the high strain rates, there is an increase in stiffness for both types of composite and a significant increase in the fracture stress, resulting in a greater fracture energy.

Figure 5 for the cross-ply (TC) materials indicates that the strain corresponding to complete fracture is approximately the same at low and high strain rates. The general shapes of the stress-strain plots for the epoxy are similar at high and low rates, i.e. the behaviour is virtually linear up to fracture. However, the stress at fracture is greater for the highest strain rates, giving a greater fracture energy. The significant difference between the APC2 plots at low and high strain rates indicates a more complex fracture process at high rates. At high strain rates there are partial fractures which occur at much lower stresses than the fracture stresses in the quasistatic tests. These partial fractures begin at higher stresses as the strain rate is increased. At the highest rates the fracture energy is comparable with the quasistatic values.

\subsection{Modulus Variation}

A theoretical estimate of the transverse Young's modulus of each composite has been made by applying the Halpin-Tsai equation [7], using published values of the quasistatic modulus of the matrix materials and of the transverse modulus of the carbon fibre, $4.0 \mathrm{GPa}$ and $16.7 \mathrm{GPa}$ respectively [5]. The predicted low strain rate modulus for both the epoxy and APC2 unidirectional composites is then $9.4 \mathrm{GPa}$, whereas it is $10.5 \mathrm{GPa}$ for the cross-ply composites; both of these values are in excellent agreement with those measured in the present study $(9.3 \pm 0.5 \mathrm{GPa}$ and $10.4 \pm 0.5 \mathrm{GPa}$, respectively).

The measured modulus values show an increase at high strain rates. This increase must be attributable to the viscoelastic matrix since the modulus of the carbon fibres is not expected to change. A theoretical estimate has again been made using the Halpin-Tsai equation but with a higher value for the matrix 
modulus appropriate to the high rate conditions. Such calculations show that for every $10 \%$ increase in the matrix modulus there would be a $4 \%$ increase in the modulus of the composite.

The strain rate sensitivity of several polymers was investigated by Parry et al [8] using a cylindrical wave propagation technique to obtain high rates. For example, they showed that as the strain rate was increased from $10^{-3} \mathrm{~s}^{-1}$ to $10^{3} \mathrm{~s}^{-1}$, there was a modulus increase of about $100 \%$ for high density polyethylene but only $25 \%$ for nylatron. The higher the quasistatic modulus of the material, the smaller was the modulus increase at high strain rates. The quasistatic moduli of the epoxy and PEEK matrices are similar to that of nylatron. If the increase in the matrix modulus is then assumed to be $25 \%$ at high strain rates, then the increase in the composite modulus should be about $10 \%$, as explained above. The present experiments indicate an increase of about $5 \%$ for the unidirectional composites and about $14 \%$ for the cross-ply types. These results are in quite reasonable agreement with prediction. However, as mentioned above, because of wave propagation effects during the first few microseconds of loading, it is possible to overestimate the strain in the first $0.5 \%$ of the recording and this can lead to an underestimate of the modulus. This is a more important consideration for the unidirectional composites since they start to become non-linear at much lower strains than the cross-ply.

The increase in the modulus values with strain rate for the epoxy composite, as reported in this paper, are not very different from those obtained by Daniel et al [9]. They conducted experiments, using a servohydraulic machine, on a similar type of transverse unidirectional epoxy composite, and found an increase in modulus of about $20 \%$ when the strain rate was increased from about $10^{-4} \mathrm{~s}^{-1}$ to $5 \mathrm{~s}^{-1}$.

\section{CONCLUSIONS}

The investigation has shown that the principal difference between the epoxy and the PEEK composites is the more linear, brittle behaviour of the epoxy type which leads to sudden fracture at lower levels of strain. For the cross-ply composites at high strain rates, the stress-strain behaviour of the PEEK type was more complex than that of the epoxy. At high strain rates, both types of material have increased Young's modulus values which are in reasonable agreement with theoretical prediction.

\section{Acknowledgments}

The author is very grateful to Dr J A Barnes of ICI Wilton Materials Research Centre for supplying the materials and for useful discussions.

\section{References}

[1] Cogswell F. N., Thermoplastic Aromatic Polymer Composites (Butterworth-Heinemann, Oxford 1992) pp. 213-221.

[2] Nicholas T., Impact Dynamics (Wiley, New York, 1982) pp. 277-332.

[3] Frantz C. E., Follansbee P. S. and Wright W. T., "Experimental techniques with the split Hopkinson pressure bar", 8th Int. Conf. on High Energy Rate Fabrication, Texas, 17-21 June 1984, I. Berman and J. W. Schroeder Eds. (ASME, New York, 1984) pp. 229-236.

[4] Parry D. J., Walker A. G. and Dixon P. R., J Phys: Meas. Sci. Technol. 6 (1995) 443-446.

[5] Frost S. R., J Composite Materials 24 (1990) 269-292.

[6] Parry D. J., Dixon P. R., Hodson S. and Al-Maliky N., J de Physique C8 4 (1994) 107-112.

[7] Morley J. G., High-Performance Fibre Composites (Academic Press, London, 1987) pp. 99-101.

[8] Parry D. J., Stewardson H. R. and Ahmad S. H. J de Physique C3 49 (1988) 689-94.

[9] Daniel I. M., Yaniv G. and Peimanidis G., J. Eng. Mat. and Technol 110 (1988) 169-173. 